\title{
PRODUÇÃO TEXTUAL NO ENSINO MÉDIO INTEGRADO: PRÁTICAS E DESAFIOS
}

\section{TEXTUAL PRODUCTION IN INTEGRATED HIGH SCHOOL: PRACTICES AND CHALLENGES}

\author{
ANDRADE, Elisângela Ladeira de Moura ${ }^{1}$ \\ FERNANDES, Julia Cristina da Costa ${ }^{2}$ \\ SANTIAGO, Léia Adriana da Silva ${ }^{3}$
}

\begin{abstract}
ReSUMO
Este artigo busca levantar o panorama das produções científicas acerca da prática da produção textual nas turmas do ensino médio integrado à educação profissional, dos Institutos Federais, no que diz respeito à significação desta atividade em sala de aula. Tratase de uma pesquisa bibliográfica, do tipo estado do conhecimento, cujas fontes são a Biblioteca Brasileira de Teses e Dissertações, os Periódicos da CAPES e anais de eventos. Buscamos publicações que discutiram essa temática na perspectiva de formação omnilateral, proposta pelo ensino técnico integrado ao ensino médio. Pouco encontramos que relacionasse de fato a produção textual nesta proposta de ensino: duas dissertações de mestrado, dois artigos e uma publicação em anais de evento. Frente ao poder emancipador da prática da produção textual no espaço escolar, constatamos que o assunto foi pouco explorado, havendo, portanto, muito ainda a ser pesquisado e trabalhado, sobretudo no que se refere à formação docente.
\end{abstract}

Palavras-Chave: Estado do Conhecimento; Produção textual; Formação Omnilateral; Ensino médio integrado; Educação profissional.

\section{ABSTRACT}

This article aims to raise the panorama of scientific productions about the practice of textual production in high school classes integrated to vocational courses of Federal Institutes, regarding the significance of this activity in the classroom. This is a bibliographic research, being a state of knowledge study, whose sources are the Brazilian Library of Theses and Dissertations, CAPES Journals and annals of events. We sought publications that discussed this theme from the perspective of omnilateral formation, proposed by vocational education

\footnotetext{
1 Mestranda em Educação Profissional e Tecnológica do Instituto Federal Goiano Campus Morrinhos. Goiás, GO, Brasil. e-mail: elisladeirama@gmail.com

2 Doutora em Educação. Professora do mestrado profissional em Educação Profissional e Tecnológica (ProfEPT). Goiás, GO, Brasil. e-mail: juliana.fernandes@ifgoiano.edu.br

${ }^{3}$ Doutora em Educação. Professora do mestrado profissional em Educação Profissional e Tecnológica (ProfEPT). Goiás, GO, Brasil. e-mail: leia.adriana@ifgoiano.edu.br
} 
integrated to high school. Little did we find that truly related textual production in this teaching proposal: two master's degree dissertations, two articles and one publication in annals of event. Facing the emancipating power of the textual production practice in the school space, we found out that the subject has been little explored and, therefore, there is still much to be researched and worked on, especially regarding teacher education.

KeYwORDS: State of knowledge; Text production; Omnilateral formation; Integrated high school; Vocational education

\section{INTRODUÇÃo}

O ensino médio integrado à educação profissional, ofertado pelos Institutos Federais de Educação, Ciência e Tecnologia, se difere dos projetos vinculados aos interesses de mercado. Trata-se de um ensino que pretende formar um profissional crítico, que seja capaz de refletir sobre sua condição social e participar das lutas em favor dos interesses da coletividade. Busca a formação omnilateral dos sujeitos.

Como formação humana, o que se busca é garantir ao adolescente, ao jovem e ao adulto trabalhador o direito a uma formação completa para a leitura do mundo e para a atuação como cidadão pertencente a um país, integrado dignamente à sua sociedade política. Formação que, neste sentido, supõe a compreensão das relações sociais subjacentes a todos os fenômenos (FRIGOTTO; CIAVATTA; RAMOS, 2012, p. 85)

O conceito de omnilateralidade é de grande importância para a reflexão em torno da educação. Marx trata da formação omnilateral como uma formação humana oposta à formação unilateral provocada pelo trabalho alienado e pela divisão social do trabalho.

Oposta à educação herdada da burguesia aos operários, a educação omnilateral sustenta uma formação humanizadora, que forma o indivíduo para o trabalho e para as relações que ele estabelece ao longo da vida. Ela prevê conhecimento e cultura, emancipando esse indivíduo. Na perspectiva freireana, o estudante deixa de ser um "depósito" de conhecimentos produzidos e transmitidos por outros e passa a construir, desconstruir e reconstruir suas próprias convicções a respeito da ciência, da tecnologia, do mundo e da própria vida.

Na concepção de Ramos (2014), a formação omnilateral sugere a formação integral dos seres humanos, entendendo-os como seres históricos e sociais, que seja capaz de formar sujeitos autônomos, que possam compreender-se no mundo e nele atuar, por meio do trabalho. 
A ideia de formação integrada sugere superar o ser humano dividido historicamente pela divisão social do trabalho entre a ação de executar e a ação de pensar, dirigir ou planejar. Trata-se de superar a redução da preparação para o trabalho ao seu aspecto operacional, simplificado, escoimado dos conhecimentos que estão na sua gênese científico-tecnológica e na sua apropriação histórico-social. Como formação humana, o que se busca é garantir ao adolescente, ao jovem e ao adulto trabalhador o direito a uma formação completa para a leitura do mundo e para a atuação como cidadão pertencente a um país, integrado dignamente à sua sociedade política. Formação que, neste sentido, supõe a compreensão das relações sociais subjacentes a todos os fenômenos (CIAVATTA, 2005 apud RAMOS, 2014, p. 86).

Nesse sentido, a formação profissional precisa estar comprometida com a formação humana, adotando o trabalho como princípio educativo. No que diz respeito à integração do ensino médio com a educação profissional, faz-se necessária a reflexão sobre o seu verdadeiro significado. O que é integrar?

Ramos (2014), citando Ciavatta (2005), nos oferece como resposta, que integrar remete ao

sentido de completude, de compreensão das partes no seu todo ou da unidade no diverso, o que implica tratar a educação como uma totalidade social, isto é, nas múltiplas mediações históricas que concretizam os processos educativos. No caso da formação integrada ou do ensino médio integrado ao ensino técnico, o que se quer com a concepção de educação integrada é que a educação geral se torne parte inseparável da educação profissional em todos os campos em que se dá a preparação para o trabalho: seja nos processos produtivos, seja nos processos educativos como a formação inicial, como o ensino técnico, tecnológico ou superior. Significa que buscamos focar o trabalho como princípio educativo, no sentido de superar a dicotomia trabalho manual / trabalho intelectual, de incorporar a dimensão intelectual ao trabalho produtivo, de formar trabalhadores capazes de atuar como dirigentes e cidadãos. (CIAVATTA, 2005, apudRAMOS, 2014, p. 87).

Integrar trabalho e educação requer uma atenção especial às determinações que os constituem. Trabalho, ciência, tecnologia e cultura são conceitos indissociáveis da formação humana.

[...] atribuímos à integração expressando uma concepção de formação humana, com base na integração de todas as dimensões da 
vida no processo educativo, visando à formação omnilateral dos sujeitos. Essas dimensões são constituídas pelo trabalho, a ciência e a cultura. O trabalho compreendido como realização humana inerente ao ser (sentido ontológico) e como prática econômica (sentido histórico associado ao modo de produção); a ciência compreendida como os conhecimentos produzidos pela humanidade que possibilita o contraditório avanço das forças produtivas; e a cultura, que corresponde aos valores éticos e estéticos que orientam as normas de conduta de uma sociedade (RAMOS, 2014, p. 87).

Na perspectiva do currículo, a contextualização é um dos eixos norteadores para educação profissional integrada ao nível médio. A contextualização faz o conteúdo ganhar sentido em razão da relação que se estabelece entre o que é ensinado/aprendido e o conhecimento situado numa dada realidade.

Essa contextualização precisa estar presente em todas as disciplinas, e abordaremos, aqui, sua importância nas aulas de Língua Portuguesa, mais precisamente nas atividades relacionadas à produção textual.

A prática da produção textual nas escolas há tempos se resume ao exercício da redação escolar como preparação para exames como vestibulares e ENEM Exame Nacional do Ensino Médio. Essa prática vigente sugere apenas uma mera reprodução de padrões de linguagem, de uma forma bem minimalista e desinteressante. Por que apenas reproduzir? Dado um tema no vazio, mero exercício de preenchimento de umas tantas linhas, escrever para ninguém ler. A escola deixa visível que esse padrão de reprodução é o único que ela aceita. Entretanto, a busca por uma formação omnilateral dos sujeitos precisa preparar e permitir muito mais do que isso.

Não estamos afirmando que a prática da escrita para a preparação dos exames não é importante. É necessário preparar os alunos para o ingresso no ensino superior. Porém, a prática da produção textual, no ambiente escolar, pode ir muito além.

É preciso buscar o uso consciente dos recursos expressivos da língua para se alcançar uma formação humanizadora, que prepare o educando para o real exercício da cidadania. Promover a capacidade de produzir textos de forma crítica, fugindo à mera (re)produção do gênero "redação escolar", e ampliando a leitura crítica da realidade tem sido objetivo de vários estudos ao longo dos anos.

É neste sentido que leitura crítica da realidade, dando-se num processo de alfabetização ou não e associada, sobretudo, a certas práticas claramente políticas de mobilização e de organização, pode 
constituir-se num instrumento para o que Gramsci chamaria de ação contra-hegemônica (FREIRE, 2011, p. 31). ${ }^{4}$

Para que a produção textual seja uma atividade escolar emancipadora, "contra-hegemônica", é necessário considerá-la num processo de construção e reconstrução, de escrita e reescrita. Guedes (2009, pp. 13-14) considera que "[...] a tarefa do professor de redação começa a partir do texto escrito pelo aluno e que essa tarefa é a orientação da reescrita desse texto para ajudar seu autor a descobrir o que ele queria dizer e a reescrever a primeira versão para fazê-la dizer isso." Pensando na perspectiva da prática da produção textual em turmas de nível médio integrado, ousamos afirmar que a tarefa do professor começa antes da orientação da reescrita do texto, começa na abordagem de temas contextualizados com a realidade dos alunos. Partindo de suas próprias realidades, com o desenvolvimento das capacidades de escrita e reescrita, vão se "libertando" para a real compreensão do mundo onde vivem e para a capacidade de atuarem criticamente neste mundo.

Nesse sentido, nas linhas que se seguem, buscamos apresentar o panorama das produções científicas acerca da prática da produção textual nas turmas do ensino médio integrado de Institutos Federais, no que diz respeito à significação desta atividade em sala de aula. Trata-se de uma pesquisa bibliográfica, do tipo estado do conhecimento, cujas fontes são a Biblioteca Brasileira de Teses e Dissertações, os Periódicos da CAPES (Coordenação de Aperfeiçoamento de Pessoal de Nível Superior) e anais de eventos. Buscamos publicações que discutiram essa temática na perspectiva de formação omnilateral, proposta pelo ensino técnico integrado ao ensino médio.

\section{O INVENTÁRIO DAS PRODUÇõES ACADÊMICAS IDENTIFICADAS}

Desde meados da década de 1980, a pesquisa do tipo Estado da Arte (tradução literal do inglês state of the art) ou Estado do Conhecimento vem sendo realizada no Brasil. Soares (1989, p. 4) afirma que

[...] são, sem dúvida, de grande importância, pois pesquisas desse tipo podem conduzir à plena compreensão ou totalidade do estado atingido pelo conhecimento a respeito de determinado tema - sua amplitude, tendências teóricas, vertentes metodológicas.

Ferreira $(2002$, p. 158) esclarece que se deve realizar esse tipo de pesquisa a partir de banco de dados diferentes, como "[...] teses de doutorado, de mestrado,

\footnotetext{
${ }^{4}$ Grifos nossos.
} 
artigos publicados em periódicos e comunicação em anais de eventos, congressos e seminários".

De acordo com a metodologia de pesquisa descrita, e utilizando os descritores (I) "produção textual ensino médio integrado", (II) "produção textual formação profissional" e (III) "produção textual educação profissional" na Biblioteca Digital Brasileira de Dissertações e Teses - BDTD e nos Periódicos da CAPES, pouco encontramos que relacionasse de fato a produção textual nestas propostas de ensino (ensino médio integrado e formação profissional). Na Scientific Electronic Library Online - SciELO, não há nenhuma publicação específica sobre o tema com os descritores citados. Buscamos, ainda, em repositórios de eventos e encontramos uma publicação que explora o assunto. Vimos que o tema é pouco explorado, o que justifica ainda mais nosso estudo.

O recorte feito foi atemporal, nos preocupamos somente com o tema, já que não há muitos estudos relacionados. Foram encontrados e considerados, aqui, duas dissertações de mestrado, dois artigos e uma publicação em anais de evento. Enfatizamos que a finalidade das pesquisas relacionadas, trata da produção textual como atividade criativa e criadora, capaz de contribuir para o processo de humanização dos sujeitos.

Apesar da escolha das pesquisas terem sido feitas considerando somente o tema, iremos organizá-las e abordá-las em ordem cronológica. Para melhor sistematizar os dados, elaboramos o Quadro 1, apresentado a seguir, para discriminar a instituição de ensino à qual o pesquisador/autor pertence, o tipo de produção acadêmica, o ano de publicação, autor e título do trabalho.

\section{Quadro 1 - Produções acadêmicas obtidas junto à BDTD, Periódicos da CAPES} e repositório do CONEDU sobre a prática da Produção Textual no ensino médio integrado à educação profissional

\begin{tabular}{|c|c|c|c|c|}
\hline Instituição & $\begin{array}{l}\text { Tipo de } \\
\text { Produção }\end{array}$ & Ano & Autores(as) & Título \\
\hline IFPA & Artigo & 2012 & $\begin{array}{l}\text { Miranilde Oliveira } \\
\text { Neves }\end{array}$ & $\begin{array}{l}\text { Oficinas de texto: um novo olhar } \\
\text { sobre a leitura e a produção } \\
\text { textual }\end{array}$ \\
\hline IFRN & $\begin{array}{l}\text { Resumo } \\
\text { simples }\end{array}$ & 2014 & $\begin{array}{l}\text { Mylenna Vieira Cacho e } \\
\text { Dante Henrique Moura }\end{array}$ & $\begin{array}{l}\text { A produção textual significativa no } \\
\text { ensino médio integrado à } \\
\text { educação profissional no IFRN }\end{array}$ \\
\hline UFSM / IFFar & Dissertação & 2017 & $\begin{array}{l}\text { Betina Waihrich Marim } \\
\text { Teixeira }\end{array}$ & $\begin{array}{l}\text { Formação permanente de } \\
\text { professores de língua portuguesa e } \\
\text { o ensino de produção textual, no } \\
\text { contexto da educação básica, } \\
\text { técnica e tecnológica }\end{array}$ \\
\hline UNEB & Artigo & 2017 & $\begin{array}{l}\text { Clebemilton Gomes do } \\
\text { Nascimento e Cleide } \\
\text { Selma Alecrim Pereira }\end{array}$ & $\begin{array}{l}\text { O jogo discursivo da escrita e } \\
\text { reescrita na aula de produção } \\
\text { textual }\end{array}$ \\
\hline
\end{tabular}


DOI: $10.12957 /$ e-mosaicos.2019.46559
UEPB
Dissertação
2019
Rosana de Oliveira Sá
Produção textual na formação profissional do aluno da EJA

Fonte: Elaborado pelas autoras com base nos dados da pesquisa.

Neves (2012), em seu artigo, objetiva relatar uma experiência que ocorreu no IFPA - Instituto Federal de Educação, Ciência e Tecnologia do Pará - Campus Tucuruí, com alunos selecionados entre as turmas do $1^{\circ}$ ao $4^{\circ}$ ano de Saneamento Ambiental, Informática e Eletrotécnica, todas pertencentes ao ensino técnico integrado ao ensino médio, sobre o processo de produção textual dos alunos envolvidos nas oficinas de texto ofertadas no Instituto e também avaliar as estratégias de leitura e produção textual, com o apoio dos professores de todas as disciplinas e outros profissionais, como juiz, defensor público, advogado, psicólogo e pedagogo. Um projeto iniciado em agosto de 2009 que se estendeu até junho de 2001, considerou a legislação vigente no país, na busca da formação de cidadãos críticos, conscientes do importante papel que desempenham na sociedade e, portanto, conhecedores de seus direitos e deveres.

Buscou mostrar que é possível apresentar o novo aos educandos sem abandonar questões pertinentes à escrita e à boa leitura. $\mathrm{O}$ novo aqui descrito, como um dos diferenciais das oficinas de texto ministradas: despertar os discentes para a importância de conhecer e lutar por seus direitos e deveres por meio do estudo da Legislação Brasileira, fazendo uso de Estatutos como o do Idoso e o da Criança e do Adolescente, da Lei Maria da Penha, do Código de Defesa do Consumidor, do valor que tem a produção de um currículo e de uma entrevista de emprego, entre outros temas que despertaram os educandos para o real desempenho de sua cidadania. Textos literários também foram abordados, na busca de uma ampliação da visão que se tem da vida e do mundo, no momento em que esse acesso é permitido.

Foram usadas estratégias cognitivas e metacognitivas. Em cada oficina era necessário ler, produzir e entender textos e para que esta atividade obtivesse sucesso, foi preciso que houvesse uma interação entre o leitor (sujeito) e o texto lido (objeto). Dessa forma, houve a construção do sentido do texto, dando atenção às estratégias cognitivas. As estratégias metacognitivas permitiram ao leitor influenciar e controlar conscientemente a ação de leitura, ou seja, a partir delas foi possível se ter um leitor capaz de refletir sobre o próprio conhecimento. A reconstrução do texto, apesar de num primeiro momento não ter sido tarefa bem aceita, acabou sensibilizando os alunos participantes para a importância que tem este trabalho de reescritura.

A autora defende que argumentação e linguagem são essenciais no trabalho com gêneros textuais diferentes. "A argumentação eficaz permitirá a tão almejada cidadania, pois só argumenta quem conhece, quem lê, quem aprende a ouvir e falar no momento exato" (Neves, 2012, p. 341). Mas conhecer apenas a Legislação Brasileira não é suficiente para se alcançar a tão desejada cidadania. O sujeito se 
completará no momento em que conhecer também a literatura da sua região, do lugar onde vive. Este é um dos fatores que fazem com que muitos de nossos escritores defendam a presença da Literatura nas escolas.

O projeto alcançou o aprimoramento das produções textuais dos alunos, pois em cada oficina sempre havia uma produção escrita ou oral. Inspirados numa visita à Academia Paraense de Letras, os educandos desejaram produzir um livro, o que foi realizado no mês de abril de 2011. Alguns escritores da Academia Paraense de Letras inclusive foram prestigiar os alunos.

A autora conclui que, em relação à cidadania, a escola cumpriu seu papel: o de tornar os alunos cidadãos críticos, conscientes de seus direitos e deveres e com boa capacidade de argumentação.

Cacho e Moura (2014), num trabalho apresentado no CONEDU - Congresso Nacional de Educação, em Fortaleza-CE, abordaram o tema "produção textual significativa no ensino médio integrado à educação profissional no IFRN". Iniciaram citando Ciavatta (2005), na conceituação da 'formação integrada', que ocorre quando a educação geral se torna parte inseparável da educação profissional, em todos os campos onde se dá a preparação para o trabalho.

Nessa perspectiva, a formação de seres críticos e cidadãos perpassa pelas disciplinas técnicas e propedêuticas, visto que somos seres histórico-sociais que atuam no mundo concreto para satisfazerem suas necessidades subjetivas e sociais, produzindo conhecimentos (CACHO; MOURA, 2014, p. 1).

Por meio da percepção da falta de interesse em leituras literárias ou acadêmicas por parte dos alunos da turma iniciante do ano letivo de 2013, nas diversas disciplinas do Curso Integrado de Química do Instituto Federal no Campus Macau, os professores de Língua Portuguesa e de Geografia repensaram juntos suas práticas pedagógicas e resolveram trabalhar de forma interdisciplinar, agregando um olhar mais consciente, reflexivo e crítico do lugar onde vivem os alunos do primeiro ano do referido curso, associado à prática de produção textual mais significativa, uma vez que vivenciaram ou ouviram histórias que aconteceram nesses lugares. $\mathrm{Na}$ perspectiva que a construção de conhecimentos acontece, a partir do local para o global, ou seja, compreender o local onde vivem para reconhecer-se como agente de transformação.

Os autores citam Lefebvre (2006), na descoberta da paisagem como ponto de partida da leitura da realidade, num espaço que é produto das relações sociais. Santos (2009), afirma que esse espaço é formado por usos distintos dos elementos naturais e dos elementos construídos pelo homem, e, por conseguinte contraditório.

A análise da paisagem, então, atentava para a compreensão da dinâmica das ações e dos interesses dos grupos sociais de suas comunidades. A leitura crítica do 
cotidiano expressa na ação e na omissão dos agentes públicos e privados instigava os discentes a perceberem que, por trás das aparências sociais, existe uma essência repleta de interesses, ganância e lucro. $O$ anseio por melhores condições de vida impulsionava-os a compreender que a produção econômica devia estar em conformidade com a produção da vida social, que, por natureza, é espacial. A mudança na escrita partiu, então, literária e socialmente falando, desta percepção da realidade.

O gênero textual escolhido foi a crônica, por ter seu eixo temático sempre em torno de uma realidade social, política ou cultural. A metodologia iniciou com a leitura do poema Infância, de Carlos Drummond de Andrade. Os autores afirmam que este poema possibilitou a compreensão de que histórias das vivências dos discentes podiam ser mais bonitas do que muitas que são mostradas em filmes e livros. A professora de Língua Portuguesa trabalhou as características de uma crônica, com exemplos em sala de aula, e solicitou aos alunos que selecionassem e levassem para leitura coletiva uma crônica enfatizando elementos como personagens e espaços encontrados no cotidiano. O professor de Geografia, paralelamente, discutia em sala conceitos de paisagem, espaço e lugar, solicitando aos alunos fotos de paisagens que compunham os lugares onde moravam. Posteriormente, chegou 0 momento da escrita.

Foram montados painéis fotográficos com as imagens produzidas pelos próprios alunos, demonstrando as paisagens dos lugares onde viviam, o que proporcionou uma leitura da realidade espacial de cada aluno, suas belezas e seus problemas. Os alunos da turma compreenderam conceitos de lugar, espaço e paisagem, passaram a olhar onde vivem com outra perspectiva e escreveram, crônicas, sobre acontecimentos e reflexões, suas realidades, desejos e anseios. Percebia-se uma melhora em relação aos aspectos gramaticais e textuais, em relação a outras produções realizadas anteriormente. Os textos passaram por processos de reescrita até chegarem ao produto final, que foi uma coletânea lançada no Dia Nacional da Poesia, no Campus Macau.

Os autores consideraram que a prática da produção textual torna-se mais significativa quando bem direcionada a um fim específico e contextualizada com a realidade. $O$ projeto contribuiu para tornar os alunos mais autoconfiantes, críticos e reflexivos, percebendo-se como seres atuantes e tornando-se cidadãos ativos.

Teixeira (2017), em sua dissertação do Curso de Mestrado do Programa de Pós-Graduação em Educação Profissional e Tecnológica do Colégio Técnico Industrial de Santa Maria/Universidade Federal de Santa Maria (UFSM, RS) em cooperação técnica com o Instituto Federal Farroupilha (IFFar), tratou da formação permanente de professores de Língua Portuguesa e o ensino de produção textual no contexto da educação básica, técnica e tecnológica. Sua pesquisa foi desenvolvida a partir da indagação sobre como ocorre a formação permanente para os professores de Língua Portuguesa e em que medida essa formação contribui para a atuação docente voltada ao ensino de produção textual, no Instituto Federal Farroupilha, Campus 
Júlio de Castilhos. Indagou em que medida as formações permanentes realizadas por esses professores têm contribuído para a melhoria do ensino de produção textual em cursos do nível médio modalidade integrado.

Realizou uma pesquisa qualitativa, com estudo de caso, cujos sujeitos foram os professores de Língua Portuguesa do IFFar - Campus Júlio de Castilhos que ministram aulas nos cursos Técnico em Agropecuária e Técnico em Informática. Os dados, segundo a pesquisadora, possibilitaram compreender o modo como esse processo de formação permanente de professores de Língua Portuguesa, voltado ao ensino de produção textual, contribui para qualificar o ensino em cursos integrados na instituição.

A pesquisadora afirma que pesquisar sobre a Educação Profissional e Tecnológica (EPT) tem constituído um foco de grande interesse, visto que a EPT tem um papel essencial na formação de profissionais, pois, além de orientar os processos de formação, integra e articula as diversas áreas do saber, e também contribui para o progresso socioeconômico colaborando no desenvolvimento das diferentes regiões. Isso evidencia a importância da preparação do docente que trabalha com a EPT, para enfrentar essa demanda do mundo do trabalho e atender os desafios que a modalidade oferece. Por isso, a necessidade da formação permanente, pois por meio da atualização, o docente pode promover um trabalho mais eficaz em sala de aula.

"Ao docente da EPT, não basta gostar de ensinar, é preciso também gostar de aprender, ou seja, de estar sempre atualizado com as demandas existentes, buscando novos conhecimentos e preparando o aluno para ser um sujeito reflexivo e crítico" (TEIXEIRA, 2017, p. 29). Tendo o ensino médio integrado à educação profissional o objetivo de disponibilizar o ensino propedêutico ao mesmo tempo que o ensino profissionalizante, considera categorias fundamentais para a formação do aluno, dentre elas o trabalho e a cultura.

Teixeira (2017) afirma que há uma lacuna sobre a escrita, e que a escola deve manter seu quadro de docentes qualificados, no caso os professores de Língua Portuguesa que ministram as aulas de produção textual para os alunos de ensino médio integrado, para que supram essa lacuna. Afirma, ainda, que o maior objetivo do professor da escola tradicional é fazer com que seus alunos saiam do ensino médio integrado aptos para enfrentar uma seleção de vagas para a graduação, com isso espera que o aluno tenha um desenvolvimento na escrita, que é a ferramenta básica para entrar na graduação. Porém, na EPT o objetivo visa oportunizar o acesso ao conhecimento, ciência e tecnologia, acumulados pela humanidade ao longo do tempo.

Uma das perguntas feitas aos professores de Língua Portuguesa foi se trabalhavam a produção textual com os alunos de acordo com os critérios estabelecidos pelo ENEM. Uma delas respondeu que 'sim', a outra que 'não somente, mas também, porque não se pode fugir da realidade em que o aluno está inserido'. Observa-se, na resposta desta última professora, que há uma concepção de que a formação do aluno não deve somente estar pautada em processos seletivos, mas sim 
de acordo com sua realidade, pois uma das possibilidades da prática docente é formar um aluno capaz de pensar e agir por si, pois o molde do aluno reprodutor de conhecimento repetido não cabe mais no contexto social em que estamos inseridos.

A pesquisadora considera que, de modo geral, o desenvolvimento da escrita dos estudantes está diretamente ligado ao modo de atuação e clareza do ensino por parte do professor, pois ele auxiliará o estudante na construção de seu conhecimento, mediando o saber já adquirido do aluno com as novas aprendizagens. Ainda, que a formação permanente implica muito nas aulas, pois a atuação dos professores possibilita diversas aprendizagens a esses alunos. Um professor com diversas experiências poderá fazer a abordagem do tema com propriedade e domínio, utilizando de metodologias diversificadas, tornando a aprendizagem significativa e instigando ao aluno a curiosidade ao aprender.

Nascimento e Pereira (2017), em artigo publicado na Revista EntreLetras, trazem o tema 'jogo discursivo da escrita e reescrita em aulas de produção textual' e o significado destas ações na formação pessoal e profissional dos futuros professores, o caráter emancipatório das práticas de leitura e como esses espaços colocam em jogo identidades instituídas e relações de poder. Objetivaram tratar dos dilemas, tensões e desafios que envolvem a escrita e a reescrita de textos nas oficinas de produção textual mediadas pelos bolsistas de iniciação à docência do PIBID-UNEB (Programa Institucional de Bolsas de Iniciação à Docência Universidade do Estado da Bahia), participantes do subprojeto Jornal escolar na docência: um artefato de aprendizagem integrado ao ensino de língua portuguesa, desenvolvido em parceria com o Colégio Estadual da Bahia-Central na cidade de Salvador-BA. Utilizaram uma metodologia interpretativa das práticas pedagógicas do dia a dia das oficinas nas aulas de Língua Portuguesa, analisando como os bolsistas ID concebem o trabalho com a escrita e reescrita textual e o significado destas ações na formação pessoal e profissional destes futuros professores de Língua Portuguesa.

Os autores fazem uma reflexão sobre a discussão acerca das aulas de produção de texto na escola: um debate antigo e que está longe de ser concluído. A leitura e a escrita na escola têm sido o centro das preocupações de linguistas aplicados, analistas de discursos, pedagogos e autores de livros didáticos. "No entanto, as subjetividades que envolvem os processos de escrita transcendem uma ótica disciplinar e revela um jogo de poderes que toma a sala de aula no sentido bakhtiniano como fenômeno social e ideologicamente constituído" (NASCIMENTO; PEREIRA, 2017, p. 327).

O professor é historicamente revertido de autoridade textual nos processos de interação discursiva em aulas de leitura e escrita, o que dificulta dar vez e voz ao aluno no ambiente escolar, pela leitura, escrita e reescrita de textos. Portanto, é necessária uma mudança significativa de atitude dos sujeitos envolvidos perante o texto, especialmente no professor, menos mecânica e mais reflexiva, mais dialógica e menos centralizadora. 
O subprojeto investiu na possibilidade de promover o envolvimento dos alunos em práticas sociais que possibilitassem a sua formação enquanto leitores, produtores maduros e críticos do mundo em que vivem, podendo se situar criticamente no mundo, percebendo-se sujeitos de sua história. Apostou na metodologia da reescrita do texto, pelos alunos, como um caminho possível para o amadurecimento da escrita e da criticidade, dialogando com as experiências dos sujeitos envolvidos. Os autores entendem que é através da reescrita que o produtor do texto pode rever sentidos pretendidos, ampliar o debate com novas ideias, refletir sobre a sua aprendizagem, interagir com a língua, acionar os conhecimentos prévios, bem como construir sentidos sobre o próprio ato de escrever. Os textos escritos e reescritos pelos alunos eram publicados em pequenos boletins e num jornal escolar que era distribuído para toda a comunidade escolar de dentro e do entorno da escola, responsabilizando, também, o aluno pelo seu dizer, já que passa a ter um leitor de seu texto que não é somente o seu professor avaliador.

Os autores ressaltam que, apesar das ações do subprojeto terem acontecido na terceira série do ensino médio, não se prenderam, somente, aos textos dissertativos cobrados no ENEM e nos vestibulares como, geralmente, ocorrem nessas séries. Todos os gêneros foram acolhidos como estímulo à escrita. Consideram que a pedagogia do trabalho com textos é um trabalho lento, de fazer, amadurecer, desconfiar, refazer, investir, desistir, construir e desconstruir.

Concluem que o trabalho pedagógico, na escola, possa seguir um caminho menos previsível, mecânico e mais libertador. Será necessário privilegiar a construção conjunta do conhecimento sobre o discurso escrito, por meio da participação ativa dos alunos, como autores e leitores, analisando textos autênticos e lendo os seus textos criticamente, buscando adequá-los às expectativas do seu público-alvo, mas, acima de tudo, fazendo encontrar os sentidos para eles mesmos.

Sá (2019), tratou da evasão de alunos do Programa Nacional de Integração da Educação Profissional com a Educação Básica na Modalidade de Educação de Jovens e Adultos (Proeja), afirmando que na análise do banco de dados de dissertações, não se encontra muitas publicações sobre propostas pedagógicas capazes de promover o processo de ensino e aprendizagem desse alunado específico, principalmente em relação às práticas de produção textual nas aulas de Língua Portuguesa. Diante disso, enquanto professora da modalidade de jovens e adultos, surgiu o interesse em desenvolver uma proposta metodológica para ressignificação do ensino de produção textual nas aulas de Língua Portuguesa no contexto do Proeja no Instituto Federal da Paraíba, Campus João Pessoa. "É necessário, então, reconfigurar o ensino de produção textual nesse Instituto em particular, no intuito de promover um aprendizado mais condizente com as demandas profissionais futuras dos alunos dessa modalidade." (Sá, 2019, p. 14)

A pesquisadora justifica sua pesquisa pelo entendimento de que as práticas de produção textual devem ser voltadas para as necessidades cotidianas do discente, oferecendo-Ihe as condições de posicionamento diante do mundo, para exercer 
plenamente sua cidadania e entender o impacto social que um indivíduo pode causar pelo bom uso da linguagem.

Como objetivo geral do estudo, trouxe o desenvolvimento de uma proposta metodológica para as aulas de Língua Portuguesa do Proeja-IFPB/JP, que tornasse possível a produção de textos multimodais condizentes com as necessidades profissionais e cotidianas dos alunos dessa modalidade de ensino, valendo-se das teorias do letramento, da multimodalidade e de projetos didáticos/temáticos. Para tanto, dentre outras ações, analisou o livro didático de Língua Portuguesa do curso a fim de verificar se as atividades de leitura e produção textual estavam em consonância com os estudos norteadores do ensino da EJA, como também com as orientações oficiais que regulam o ensino médio.

Realizou uma pesquisa de natureza qualitativa, descritiva e interpretativista. Os dados foram gerados por meio de diferentes instrumentos, tais como: observação participante, diário de pesquisa, registro fotográfico, gravações de áudio e produções textuais dos discentes em estudo.

Importante ressaltar que, em seu estudo, atestou por meio do Documento Base (BRASIL, 2007) da Educação de Jovens e Adultos, em especial ao Proeja, que essa modalidade de ensino caracteriza-se por atender um grupo composto, basicamente, por trabalhadores com experiências escolares marcadas por períodos de afastamento e por reprovações. Portanto, os conhecimentos de leitura e de produção textual dos sujeitos do Proeja não se constroem, exclusivamente, pela escolarização, mas também por saberes que vêm de outros contextos, das interações sociais e das diversificadas experiências pessoais e profissionais. Por isso a viabilidade da inserção de práticas de letramento no processo de ensino e aprendizagem desses educandos. Neste contexto, com a pretensão de educar para o pleno exercício da cidadania, faz-se necessário reconfigurar as práticas de letramento desenvolvidas na sala de aula, alinhando-as às necessidades cotidianas dos discentes e desenvolvendo-as na perspectiva das práticas sociais, visando romper com o modo descontextualizado de ensinar, ainda muito vigente em muitas instituições de ensino.

A pesquisadora afirma que o ensino voltado para práticas de letramento que incentivam a vivência da cidadania minimiza os efeitos das desigualdades sociais. Mas considera, no desenrolar de sua pesquisa, que trabalhar com projetos de letramento escolar que valorizam a leitura e a escrita para o exercício da cidadania é importante, mas não é o bastante para a articulação da linguagem e cidadania, no contexto escolar. Esse tipo de prática pedagógica requer um (re)posicionamento identitário do docente e das escolhas teórico-metodológicas feitas por ele, a fim de promover uma melhor articulação entre teoria e prática. 


\section{CONSIDERAÇõES FINAIS}

Abordamos, então, pesquisas que tratam da produção textual, na perspectiva do ensino técnico integrado ao ensino médio, como instrumento desenvolvedor da criatividade e criticidade dos sujeitos. Ressaltamos que há quase uma unanimidade na busca pela significação ou ressignificação da produção textual no espaço escolar, como uma linguagem fundamental para a participação do sujeito na sociedade, ou seja, instrumento para o exercício da cidadania.

Na perspectiva da formação omnilateral proposta pelo ensino médio integrado à educação profissional, é imprescindível trabalhar a produção textual como uma atividade emancipadora, partindo da realidade dos alunos, em um processo de construção e desconstrução do texto, até se alcançar o fim libertador inerente à atividade.

Por fim, na pesquisa das publicações, percebemos o quanto ainda é rara a abordagem dessa temática relacionada à educação integrada. Ainda há muito o que ser pesquisado e trabalhado, considerando, inclusive, a formação de professores. Pois, conforme afirmaram Nascimento e Pereira (2017, p. 327), é necessária "uma mudança significativa de atitude dos sujeitos envolvidos perante 0 texto, especialmente no professor, menos mecânica e mais reflexiva, mais dialógica e menos centralizadora".

\section{RefERÊnCIAS}

BRASIL. Ministério da Educação. Educação Profissional Técnica de Nível Médio Integrada ao Ensino Médio. Documento Base. Brasília, DF: MEC, 2007.

CACHO, M. V.; MOURA, D. H. A Produção textual significativa no ensino médio integrado à educação profissional no IFRN. In: Congresso Nacional de Educação, 1, 2014, Campina Grande. Anais Conedu, S.I.: Ifrn, 2014. v. 1, p. 1 - 5. Disponível em: <http://memoria.ifrn.edu.br/bitstream/handle/1044/391/ModalMylennaCONEDU.pdf?sequence=1>. Acesso em: 30 out. 2019.

FERREIRA, Norma Sandra de Almeida. As Pesquisas denominadas "Estado da Arte". Educação \& Sociedade, São Paulo, ano 23, n. 79, ago. 2002. Disponível em: <http://www.scielo.br/pdf/es/v23n79/10857.pdf>. Acesso em: 02 nov. 2019.

FREIRE, P. A importância do ato de ler: em três artigos que se completam. 51. ed. São Paulo, SP: Cortez, 2011. 
FRIGOTO, G.; CIAVATTA, M.; RAMOS, M. (org). Ensino Médio integrado: concepção e contradições. São Paulo: Cortez, 2012.

GUEDES, P. C. Da redação à produção textual: o ensino da escrita. São Paulo: Parábola Editorial, 2009.

LEFEBVRE, H. A produção do espaço. Trad. Doralice Barros Pereira e Sérgio Martins (do original: La production de l'espace. 4 éd. Paris: Éditions Anthropos, 2000). Primeira versão: início - fev.2006

NASCIMENTO, Clebemilton Gomes; PEREIRA, Cleide Selma Alecrim. O jogo discursivo da escrita e reescrita na aula de produção textual. EntreLetras, Araguaína - TO, v. 8, ed. 2, p. 326-339, 1 dez. 2017. Disponível em:

<https://sistemas.uft.edu.br/periodicos/index.php/entreletras/article/view/4028> Acesso em: 30 out. 2019

NEVES, Miranilde Oliveira. Oficina de texto: um novo olhar sobre a leitura e a produção textual. Signo, Santa Cruz do Sul, v. 37, n. 62, p. 335-347, jan. 2012. DOI http://dx.doi.org/10.17058/signo.v37i62.2314. Disponível em:

<http://online.unisc.br/seer/index.php/signo/article/view/2314>. Acesso em: 30 out. 2019.

RAMOS, Marise Nogueira. História e política da educação profissional. Curitiba, PR:

Instituto Federal do Paraná, 2014. Disponível em:

$<$ http://curitiba.ifpr.edu.br/wpcontent/

uploads/2016/05/Hist\%C3\%B3ria-e-pol\%C3\%ADtica-daeduca\%

C3\%A7\%C3\%A3o-profissional.pdf >. Acesso em 02 nov. 2019.

SÁ, R. O. Produção textual na formação profissional do aluno da EJA. 2019. 197 f. Dissertação. (Mestrado Profissional em Formação de Professores) Universidade Estadual da Paraíba, Campina Grande.

SANTOS, M. A Natureza do espaço: técnica e tempo, razão e emoção. 4 ed. São Paulo: Edusp, 2009.

SOARES, M. B. Alfabetização no Brasil: o Estado do Conhecimento. Brasília: INEP/Santiago: Reduc, 1989.

TEIXEIRA, B. W. M. Formação permanente de professores de língua portuguesa e o ensino de produção textual, no contexto da educação básica, técnica e tecnológica. 2017. 99 f. Dissertação. (Mestrado do Programa de Pós-Graduação em Educação Profissional e Tecnológica do Colégio Técnico Industrial de Santa Maria/UFSM, RS em 
DOI: $10.12957 /$ e-mosaicos.2019.46559

\section{cooperação técnica com o Instituto Federal de Farroupilha - IFFar) Universidade Federal de Santa Maria, Santa Maria.}

Recebido em 09 de novembro de 2019

Aceito em 07 de dezembro de 2019

(C) $(1) \otimes$

A e-Mosaicos Revista Multidisciplinar de Ensino, Pesquisa, Extensão e Cultura do Instituto de Aplicação Fernando Rodrigues da Silveira (CAp-UERJ) está licenciada com uma Licença Creative Commons - Atribuição-NãoComercial 4.0 Internacional.

Os direitos autorais de todos os trabalhos publicados na revista pertencem ao(s) seu(s) autor(es) e coautor(es), com o direito de primeira publicação cedido à e-Mosaicos.

Os artigos publicados são de acesso público, de uso gratuito, com atribuição de autoria obrigatória, para aplicações de finalidade educacional e não-comercial, de acordo com o modelo de licenciamento Creative Commons adotado pela revista. 